\title{
Stability of cupuaçu (Theobroma grandiflorum) nectar during storage
}

\author{
Margarida C. Vieira ${ }^{a, b *}$ And Cristina L. M. Silva ${ }^{c}$ \\ ${ }^{a}$ Instituto Superior de Engenharia, Universidade do Algarve, Campus da Penha, 8005-139 Faro, Portugal \\ b CIQA - Centro de Investigação em Química do Algarve, Departamento de Química e Farmácia, Faculdade de \\ Ciências e Tecnologia, Universidade do Algarve, Campus de Gambelas, 8005-139 Faro, Portugal \\ ${ }^{\mathrm{c}}$ CBQF - Centro de Biotecnologia e Química Fina - Laboratório Associado, Escola Superior de Biotecnologia, \\ Universidade Católica Portuguesa/Porto, Rua Dr. António Bernardino de Almeida, 4200-072 Porto, Portugal \\ ${ }^{*}$ Corresponding author \\ mvieira@ualg.pt \\ TEL: +351-289-800151 \\ FAX: $+351-289-888405$
}

Received: 30 October 2012; Published online: 18 October 2014

\begin{abstract}
A shelf-life study on cupuaçu nectar (Theobroma grandiflorum) was carried out in two parts. Part I studied the microbial stability of the regular nectar (batch $\mathrm{R}$ ) and the same nectar fortified with synthetic ascorbic acid $(A A)$ (batch $F$ ), pasteurized at $90{ }^{\circ} \mathrm{C}$ for $3 \mathrm{~min}$ and hot filled in glass bottles. Total Plate Count (TPC), yeast and molds as well as $\mathrm{pH}$, total soluble solids (TSS), titratable acidity and hidroxymethylfurfural (HMF) were followed along 43 storage days at 4,25 and $35{ }^{\circ} \mathrm{C}$. At the end of the storage period neither TPC nor molds or yeast had recovered the initial loads observed before pasteurization, for both $\mathrm{R}$ and $\mathrm{F}$ batches. Right after pasteurization, acidity increased slightly, $\mathrm{pH}$ decreased from 3.52 to 3.3 , and TSS increased from 18.7 to $19.0^{\circ}$ Brix, with all stabilizing afterwards. Part II evaluated ascorbic $(A A)$ and dehydroascorbic $(D H A A)$ acids' stabilization in the two batches, $\mathrm{R}$ and $\mathrm{F}$, and dissolved oxygen (DO) was monitored. Both batches were stored at the same temperatures as in Part I for two months. For batch $\mathrm{R}$, the $A A$ degradation results followed a reversible first order reaction $\left(E a_{A A(R)}=-34 \pm 6 \mathrm{~kJ} / \mathrm{mol}, k_{A A(R) 25^{\circ} C}=0.006 \pm 0.003\right.$ days $^{-1}, C_{0 A A(R)}=0.92 \pm 0.01$ and $\left.C_{\infty A A(R)}=0.43 \pm 0.19\right)$. For the $(\mathrm{F})$ nectar, the experimental data fitted a first order model well $\left(E a_{A A(F)}=30 \pm 17 \mathrm{~kJ} / \mathrm{mol}, k_{A A(F) 25^{\circ} C}=0.0016 \pm 0.0004\right.$ days $\left.^{-1}\right)$. DO was modeled as a fractional conversion model $\left(E a_{D O}=67 \pm 17 \mathrm{~kJ} / \mathrm{mol}, k_{D O 25^{\circ} C}=1.94 \pm 0.94\right.$ days $^{-1}, C_{0 D O}=0.97 \pm 0.03$ and $C_{\infty D O}=$ $0.55 \pm 0.01$ ). For both nectars, storage at environmental temperatures was preferred ( $A A$ retention above $80 \%$ ) to refrigeration, due to the slower rate of diffusion of DO at lower temperatures.
\end{abstract}

Keywords: Shelf-life; Cupuaçu nectar; Ascorbic acid; Dissolved oxygen; stability and modeling

\section{Introduction}

Cupuaçu (Theobroma grandiflorum) is an amazonian fruit from the northeast of Brazil in the state of Pará. Due to its low sugar content, it is only edible as a flavoring agent in other foods such as nectars, cakes and marmalades. Regarding nectars, several recipes can be found in the re- gion, but the more commonly preferred one contains $25 \%$ of pulp and $15 \%$ of sugar in water, with a pH of 3.2 and $18{ }^{\circ}$ Brix (Silva, 1998). Regarding preservation in nectars' processing, if a hygienic procedure is used throughout the whole process and if the $\mathrm{pH}$ is kept under 4.3, a pasteurization process should be sufficient to produce a safe juice, with a $5 D$ reduction of the tar- 
get microorganism, as suggested by the FDA regulations (FDA, 1998), during the pre-established shelf-life period and until the package is opened (Mcintyre, Ikawa, Parkinson, Haglund, \& Lee, 1995). One of the most commonly used systems in thermal preservation of nectars and juices, is the hot fill and hold process. The product is heated to $90-95{ }^{\circ} \mathrm{C}$ with a holding time of $15-20$ sec, followed by a cooling period to $82-88^{\circ} \mathrm{C}$ before filling the product into the package (glass, cans, laminated board cartons or plastic). Next it is held hot for about $2 \mathrm{~min}$, before the packages are cooled down in a cooling tunnel (Solberg, Castberg, \& Osmunsen, 1990).

For cupuaçu nectar, vitamin $\mathrm{C}$ was considered the most important quality attribute. Its degradation under thermal processing was studied and mathematically modeled (Vieira, Teixeira, \& Silva, 2000). However, after thermal preservation it is important to know how stable the product will be during storage. Barbosa, Hunn, Nazare, and Nagata (1979) reported a comparative study on shelf life of nectars of cupuaçu, bacuri (Platonia insignis) and muruci (Byrsonima crassifolia). Though the proportions of water, pulp and sugar were not stated, they reported that the soluble solids were $14{ }^{\circ}$ Brix. The nectars were pasteurized at $90{ }^{\circ} \mathrm{C}$ for $30 \mathrm{sec}$, canned and stored at $28{ }^{\circ} \mathrm{C}$. No chemical preservatives were added. From the three fruits studied, cupuaçu had the best performance, though it was reported that during the shelf life period vitamin $\mathrm{C}$ was degraded. Moreover, Oliveira (1981) studied the influence of citric acid addition (1-2 g/l) on the stability of canned cupuaçu nectar (17\% of pulp and $15.2 \%$ of sugar in water). After a thermal preservation procedure $\left(70{ }^{\circ} \mathrm{C}\right.$ during $3 \mathrm{~min}$, before canning, and $15 \mathrm{~min}$ at $100{ }^{\circ} \mathrm{C}$ in a retort), the cans were stored at $25{ }^{\circ} \mathrm{C}$. Ascorbic acid stability was measured over a period of six months. An increase in the reducing sugars, with a consequent decrease in sucrose, and a decrease in vitamin $\mathrm{C}$ were observed.

The vitamin $\mathrm{C}$ degradation mechanism is well known, being specific of a particular system, as it depends on several factors (Tannenbaum, 1976). Work on the influence of $\mathrm{pH}$, oxygen (EisonPerchonok \& Downes, 1982), cupric-ion (Hsieh \& Harris, 1987; Sahbaz \& Somer, 1993), sucrose (Hsieh \& Harris, 1987; Hsieh \& Harris, 1993), en- zymes and aminoacids (Jung, Kim, \& Kim, 1995) on the rate of ascorbic acid degradation greatly contributed to a better knowledge of the behavior of ascorbic acid in different systems during storage. In the aerobic pathway, oxidation can follow a catalyzed pathway due to the presence of metals, or an uncatalysed pathway, both leading to dehydroascorbic acid $(D H A A)$, which then degrades into 2,3-diketogulonic acid (DKGA). In the anaerobic pathway, the intermediate ketoascorbic acid is formed by ketonization, which is in equilibrium with its anion (keto-monoanion ascorbic acid), and then, through delactonization, forms DKGA (Tannenbaum, 1976).

In fruit juices' processing, $A A$ can suppress enzymatic browning by reversing the oxidation of polyphenols to o-quinones, which can polymerize forming brown pigments (Sawamura, Takemoto, Matsuzaki, Ukeda, \& Kusunose, 1994). In citrus products, the browning process is not enzymatic, starting with the degradation of $D H A A$ to form several ozones, which through the Maillard reaction produce browning compounds regardless of the presence of oxygen. The occurrence of browning can, therefore, be avoided by preventing further degradation of $D H A A$ (Sawamura et al., 1994).

In packed juices, oxygen can exist dissolved in the juice and in equilibrium with the oxygen initially present in the headspace during the filling process, and can also permeate through the package during its shelf-life. Marshall, Nagy, and Rouseff (1986) alerted to the fact that aseptic processing (as an alternative to hot-fill and hold processing) would only impart a higher quality to fruit juices that were consumed in a short period of time after thermal processing. If stored for long periods of time (more than 1 month), the higher oxygen content (as a result of processing type) would cause a decrease in quality through the appearance of non-enzymatic browning, unpleasant flavors and higher degradation of ascorbic acid. De-aeration would not improve the situation, as ascorbic acid would then follow an anaerobic pathway leading to browning as well. However, the use of a package with very low or no permeability, and by replacement of the existing air in the headspace with nitrogen, would decrease considerably the rate of ascorbic acid degradation. The package choice is therefore very im- 
portant, as mentioned above, for the extension of shelf life. A study by Bissett and Berry (1975) revealed that glass bottles, followed by foiled lined fiberboard, were the packages that better prevent ascorbic acid degradation, due to their low permeability to oxygen. In another study on orange juice (Ayhan, Yeom, Zhang, \& Min, 2001) it was concluded that flavor, vitamin $\mathrm{C}$ and color were better retained in glass and $\mathrm{PET}$, rather than in HDPE.

Nevertheless the fruit juice industry adopted, as a common practice, the addition of crystalline $A A$ to juices (Wang, Seib, \& Ra, 1995) to make up for losses during processing and storage.

Based on the above, a study on the influence of the dissolved oxygen on the $A A$ stability during storage of cupuaçu nectar, pasteurized by hot filling in glass bottles, with and without synthetic $A A$ added, was carried out.

\section{Materials and Methods}

\subsection{Cupuaçu nectar preparation}

Cupuaçu pulp was imported frozen from Belém, Brazil, and stored at $-20{ }^{\circ} \mathrm{C}$. Just before the experiments, it was taken out of the freezer and cut into small chunks. Refined sugar plus deionized water were then added to the pulp in order to obtain a nectar with the preferred formulation in the State of Pará, Brazil (25\% pulp and 15 $\%$ sugar). Preliminary sensory experiments confirmed that this is the optimum mixture, in terms of consumer acceptance. The mixture was homogenized with a Moulinex Turbomix 2 blender during $5 \mathrm{~min}$ and passed through a plastic screen. A Brix of $18^{\circ}$ and $\mathrm{pH}$ of 3.2 were measured with a hand-held refractometer (Atago Type N1 refractometer, Atago Co., Tokyo, Japan) and a glass electrode pH meter (microph 2001, Crison Instruments S. A., Spain), respectively.

Two different batches of cupuaçu (Theobroma grandiflorum) nectar ( $\mathrm{R}$, regular; and $\mathrm{F}$, fortified with $100 \mathrm{mg}$ synthetic ascorbic acid (Merck)/100 $\mathrm{ml}$ of nectar) were prepared in subsequent days, following the methodology described above.

\subsection{Thermal treatment}

For cupuaçu nectar, an acid product, the hot filling process methodology was considered sufficient to reduce the pathogenic and deteriorative flora to an acceptable level (Silva \& Silva, 1997). Based on a study (Tchango, Tailliez, Eb, Njine, \& Hornez, 1997) on tropical fruit nectars (guava and passion fruit) the most heat resistant yeast Candida pelicullosa was considered as the target microorganism $\left(\mathrm{D}_{90^{\circ} \mathrm{C}}=0,5 \mathrm{~min}\right.$ and $\mathrm{z}=34,84$ ${ }^{\circ} \mathrm{C}$ ) to obtain at least $6 \mathrm{D}$ reduction. For each batch, the nectar was pasteurized using the pasteurizer FT-40 (Armfield, Ringwood, England), where the nectar was heated up to $90{ }^{\circ} \mathrm{C}$ and then held for $3 \mathrm{~min}$ at this temperature. The nectar was then hot filled into $200 \mathrm{ml}$ bottles, previously sanitized in boiling water. The bottles were capped, inverted for $3 \mathrm{~min}$, in order to sterilize the caps, and then cooled down in a water bath. The bottles were filled leaving $1 \mathrm{~cm}$ of head space.

\subsection{Accelerated shelf life study}

In accelerated shelf life tests, samples of the food to be studied are stored under abusive temperatures, allowing the monitoring of the quality attributes of interest at pre-established time intervals in order to generate kinetic plots or shelf life charts (Pedro \& Ferreira, 2006). The study was divided in two parts. In part I, to evaluate the efficiency of the applied pasteurization method in terms of these nectars' safety and thermal impact, Total Plate Count (TPC), yeast and molds, as well as pH, total soluble solids (TSS) measured in ${ }^{\circ}$ Brix, titratable acidity, and hidroxymethylfurfural (HMF) as a color indicator (browning index due to severe heat treatments) were monitored for 43 days. In part II, the stability of vitamin $\mathrm{C}$, in its two biological forms $\mathrm{AA}$ and DHAA, was followed over 2 months along with dissolved oxygen DO.

Cupuaçu nectar was packed in glass bottles, previously labeled and identified, and caped with twist-off caps with polyurethane insulation. Bottles were placed in three temperature controlled chambers (Fitoclima model D1200PH, Aralab, S. Domingos de Rana, Portugal), previously set

IJFS | October 2014 | Volume 3 pages 160-174 
at $4 \pm 1{ }^{\circ} \mathrm{C}$ (refrigeration temperature), $25 \pm 1{ }^{\circ} \mathrm{C}$ and $35 \pm 1{ }^{\circ} \mathrm{C}$ (considered to be abusive temperatures for refrigerated products).

\section{Safety and thermal impact study - Part I}

According to a pre-established experimental plan, two bottles of each kind of nectar were taken out of each storage chamber for microbiology, acidity and hidroxymethylfurfural (HMF) evaluation. TSS and $\mathrm{pH}$ were measured only in one bottle.

\section{Microbiological evaluation}

Microbial quality was evaluated considering only the native loads of the samples. Total plate count (TPC) at $30{ }^{\circ} \mathrm{C}$, and yeasts and molds analysis were carried out by colony manual plate counting in duplicate. TPC grew in PCA (Plate Count Agar) after incubation at $30{ }^{\circ} \mathrm{C}$ for $24 \mathrm{~h}$, according to the method described in EN ISO 4833 (2003). Yeast and mold's colonies were counted after development at $25{ }^{\circ} \mathrm{C}$ for $120 \mathrm{~h}$ on the solid medium culture called Rose Bengal, according to the Portuguese standard NP-3277-1 (IPQ, 1987).

\section{Microbiological evaluation}

The $\mathrm{pH}$ was measured using a digital $\mathrm{pH}$ meter (micropH 2001: Crison Instruments, SA, Barcelona, Spain) previously calibrated with buffer solutions of $\mathrm{pH} 4.0$ and 7.0. Acidity was evaluated by a titrimetric method using $\mathrm{NaOH}$ $0.1 \mathrm{~N}$ and phenolphthalein as an indicator, and expressed in terms of citric acid according to the ISO 750, 1998 (E) method. Soluble solids were quantified with a refractometer (ATAGO - ATC1, Atago Co., Ltd., Tokyo, Japan) (0-32 ${ }^{\circ}$ Brix) (ISO 2173, 1978 - E). Finally, HMF was measured by HPLC at the Center of Food Quality (CEQA), Escola Superior de Biotecnologia Portuguese Catholic University.

\section{Vitamin C stability study - Part II}

In this study the most sensitive quality attribute was considered to be vitamin $\mathrm{C}$, in the two biological forms $A A$ and $D H A A$. According to a pre-established experimental plan, 3 bottles were taken out of each chamber for $A A, D H A A$ and dissolved oxygen (DO) evaluation, for each kind of nectar ( $\mathrm{R}$ and $\mathrm{F}), 3$ times during the first week and then 1 time per week for the next 2 months.

\section{Dissolved oxygen (DO) evaluation}

$D O$ was measured, in one bottle of each kind of nectar ( $\mathrm{R}$ and $\mathrm{F}$ ), by opening it and immediately inserting an Oxi 340 oxygen electrode, equipped with a CellOx 325 probe, previously calibrated with an air calibration beaker oxicallSL (WTW Wissenschaftlich Technische, Weinheim, Germany). The reading was carried out very rapidly, to avoid oxygen diffusion to the surface and to the air. When the study began, the samples presented values of $\cong 10 \mathrm{ppm}$. As there were no significant differences between the values for each kind of nectar the values were averaged over the study.

\section{Vitamin $\mathrm{C}$ analysis}

For each experiment, $A A$ and $D H A A$ contents were determined experimentally by HPLC UV detection and using iso-ascorbic acid (IAA) (Fluka) as an internal standard, according to the method developed by Zapata and Dufour (1992) and adapted by Vieira et al. (2000).

In the cupuaçu fruit, the content of the two forms of vitamin $\mathrm{C}$ is not constant, leading to variations in the initial concentration of ascorbic and dehydroascorbic acids in the raw nectar. To obviate this problem, the concentrations obtained after the thermal treatment were divided by the corresponding initial concentrations in order to obtain relative degradations of the vitamins $\mathrm{C}$ forms.

\section{Mathematical modeling}

To mathematically model the change for each reactant ( $A A, D H A A$ and $D O)$, a plot of concentration versus time for each storage temperature was first produced. By observation of these plots the apparent reaction order $(n)$ for each reactant $(r)$ was assumed, and the corresponding rate constants $(k)$ were determined by fitting models to the data. 
The first order model (eq. 1) was tried,

$$
\frac{C_{r(t)}}{C_{r 0}}=e^{-k t}
$$

where $\mathrm{C}$ is concentration, $\mathrm{k}$ the reaction rate, $\mathrm{t}$ the time, subscript 0 indicates the initial value and subscript (t) at time $\mathrm{t}$.

and when reversibility seemed to occur, as in the case of the well-known equilibrium between $A A$ and $D H A A$ (Vieira et al., 2000) (eq. 2),

$$
A A \rightleftharpoons D H A A
$$

a modified version of the first order reaction, named reversible reaction or fractional conversion reaction, was applied (eq. 3).

$$
\frac{C_{r(t)}-C_{r \infty}}{C_{r 0}-C_{r \infty}}=e^{-k t}
$$

where subscript $\infty$ indicates the value at equilibrium.

It was also verified if the reaction rate temperature dependence followed the Arrhenius behavior (eq. 4).

$$
k_{T}=k_{r e f} e^{\left[-\frac{E a}{R}\left(\frac{1}{T}-\frac{1}{T_{\text {ref }}}\right)\right]}
$$

where $k_{\text {ref }}$ is the reactant $(A A, D H A A$ or $D O)$ rate constant at the reference temperature $(25$ $\left.{ }^{\circ} \mathrm{C}\right), E_{a}$ is the activation energy, and $R$ the universal gas constant $(8.314 \mathrm{~J} / \mathrm{mol} \mathrm{K})$.

\section{Statistical Analysis}

Model fitting was tested by evaluating the residuals' distribution, normality and determination coefficient $\mathrm{R}^{2}$. A one-step procedure was next tried to reduce the standard deviation in $k_{\text {ref }}$ and $E_{a}$, by performing a non-linear regression through all the data points in order to calculate $E_{a}$ and $k_{r e f}$ from the original data (Arabshahi \& Lund, 1985). The Statistical Software (Stata Corporation, 1995) was used.

\section{Results and Discussion}

\subsection{Safety and thermal impact study - Part I}

From the observation of Figure 1 both molds and yeast had a $3.5 \mathrm{D}$ reduction after pasteurization for both kinds of nectar. Afterwards a recovery is observed, with more extension for the $\mathrm{R}$ nectar. No effect on total counts was noticed right after pasteurization, but the counts decreased throughout the storage period. At the end of the storage period all the counts were below $3 \mathrm{log}$ $\mathrm{CFU} / \mathrm{mL}$, with the exception of molds for the $\mathrm{R}$ nectar under refrigeration, which might be due to contamination through the lid. TPC and yeasts for the $\mathrm{F}$ nectar at $35{ }^{\circ} \mathrm{C}$ presented a high value at 30 days of storage, but by the end of the study the values were also below $3 \log \mathrm{CFU} / \mathrm{mL}$. Following the suggestion of Sampedro, Geveke, Fan, Rodrigo, and Zhang (2009), the shelf life time of cupuaçu nectar was considered to correspond to the duration of this research study, once the majority of counts were below the initial ones before pasteurization.

As far as acidity is considered, the $\mathrm{pH}$ decreases right after pasteurization and from then on remains constant at a value around 3.4 (Figure 2). Titratable acidity increases also just after pasteurization, confirming the $\mathrm{pH}$ behavior, and then remains constant till the end of storage (Figure 3). TSS also increases right after pasteurization (Figure 4). The HMF results were not detectable $(<1.0 \mathrm{mg} / \mathrm{L})$ throughout the study, indicating that the pasteurization conditions were not too severe to produce browning. On a study of cashew apple juice, Damasceno, Fernandes, Magalhaes, and Brito (2008) showed that at 100 ${ }^{\circ} \mathrm{C}$ more than 100 min were needed to detect formation of $\mathrm{HMF}$.

\subsection{Vitamin C stability study - Part II}

Figure 5 presents the experimental results of vitamin $\mathrm{C}$ (expressed as $A A$ and $D H A A$ ) and $D O$, in the $\mathrm{R}$ and $\mathrm{F}$ nectars, as a function of storage temperature and time. It can be observed that for nectar $\mathrm{R}$, stored at $4{ }^{\circ} \mathrm{C}$, there is a noticeable 
Cupuaçu nectar stable storage $\mid 165$

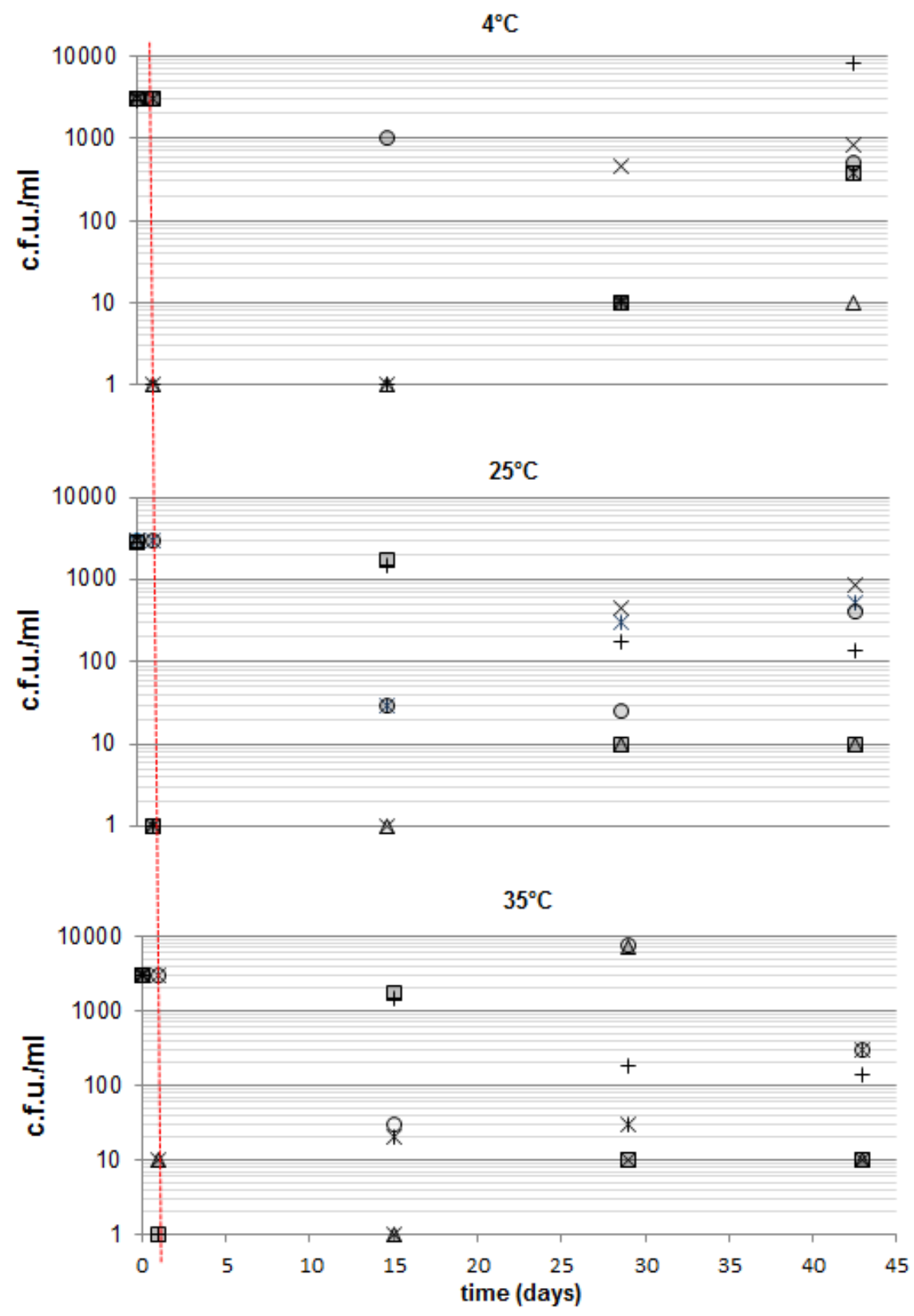

Figure 1: Evolution of total counts, yeasts and molds with storage time and at temperatures of 4,25 and $35^{\circ} \mathrm{C}$. Total plate counts: R $(*), F(\circ)$; Yeasts: R $(x), F(\triangle)$; Molds: R $(+), F(\square)$. Day 0 is before pasteurization and day 1 (marked with a vertical red dashed line) is the first day of storage. 


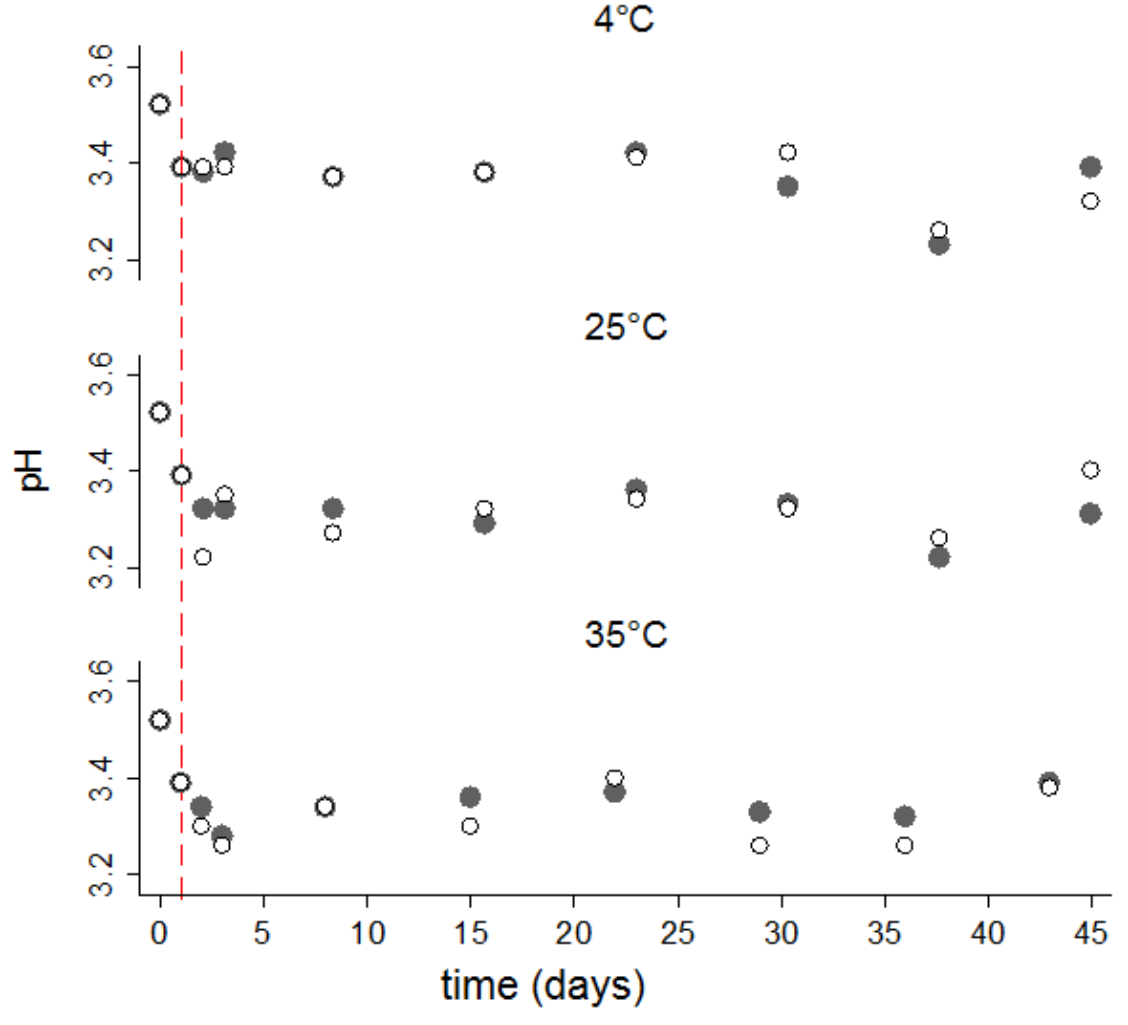

Figure 2: Evolution of $\mathrm{pH}$ with storage time and at temperatures of 4,25 and $35{ }^{\circ} \mathrm{C}$. Batch $\mathrm{R}(\mathrm{o})$, batch $\mathrm{F}(\bullet)$. Day 0 is before pasteurization and day 1 (marked with a vertical red dashed line) is the first day of storage.

decrease in $A A$. At 25 and $35{ }^{\circ} \mathrm{C}$, a decrease is also observed, but only for a short period of time ( \pm 3 days). After that period, the rate of degradation of $A A$ seems to have slowed down reaching a plateau. This trend of $A A$ experimental values suggested that for batch $\mathrm{R}$ the degradation reaction followed a reversible first order model, with the reaction rate temperature dependence following the Arrhenius behavior (Eqs. 3 and 4). For the F nectar, hardly any decrease was noticed at $4{ }^{\circ} \mathrm{C}$, but when stored at the higher temperatures, a slight decrease was noticed. A first order model, with the reaction rate temperature dependence following the Arrhenius behavior (Eqs. 1 and 4), was used to model this behavior (if the time of study was extended, probably a curvature would be seen in the predicted line).
The models' ability to fit the experimental values are presented in Figure 6. For both the R and $\mathrm{F}$ nectars the models and the corresponding kinetic parameters estimated by a one-step non-linear regression to all data of normalized concentration as a function of time at constant temperature are presented in Table 1.

The $A A$ degradation behavior of the $\mathrm{R}$ nectar, as referred above, is dependent on the oxygen intervention on the degradation reaction, as opposed to the fortified nectar where it seems to have no effect. This is probably due to two facts:

- the quantity of ascorbic acid is much higher and no changes occurred, and

- vitamins in a synthetic form are more resistant than the biologic form. 


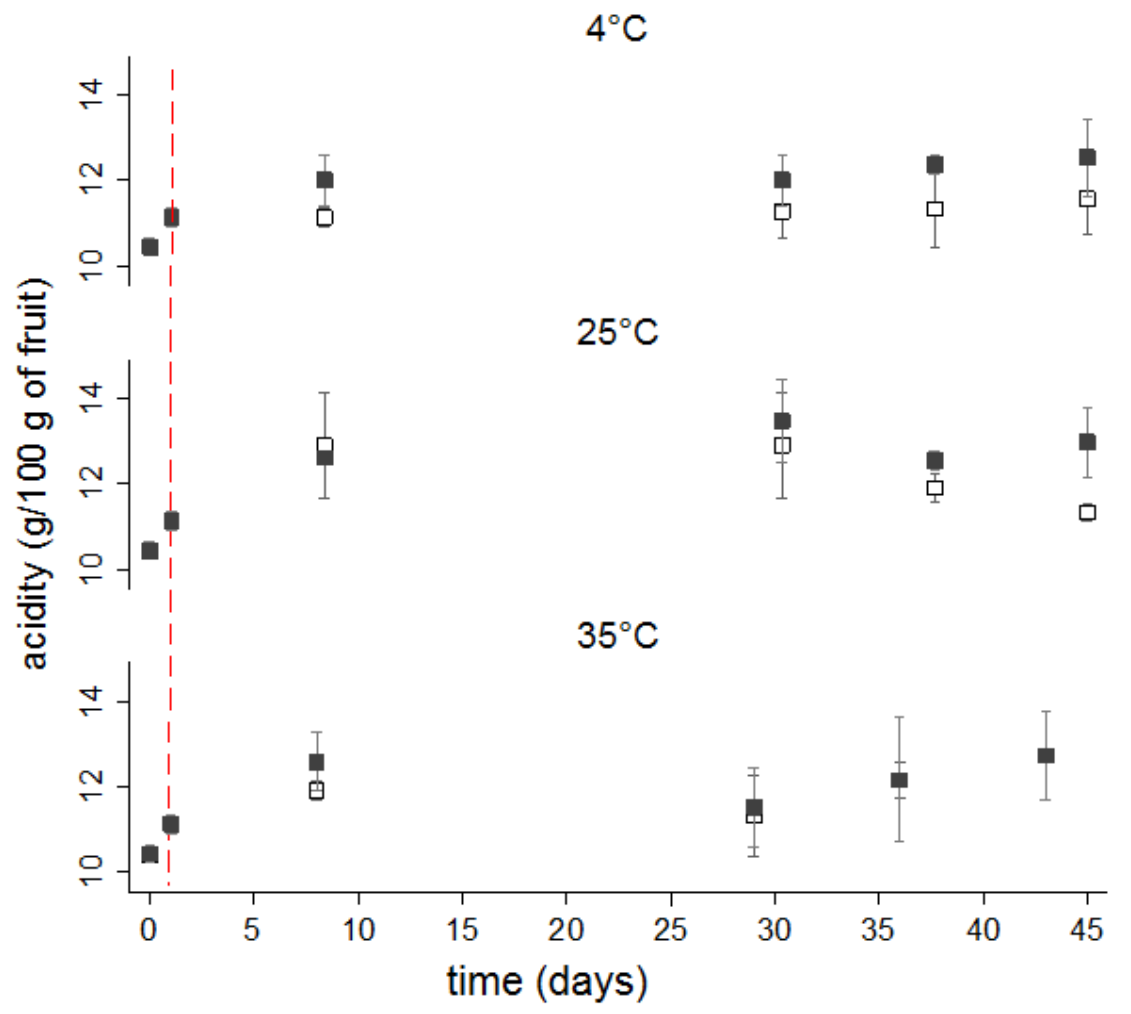

Figure 3: Evolution of acidity with storage time and at temperatures of 4,25 and $35{ }^{\circ} \mathrm{C}$. Batch R ( $\square$ ), batch F ( $\mathbf{-})$. Day 0 is before pasteurization and day 1 (marked with a vertical red dashed line) is the first day of storage.

Table 1: Kinetic parameters of $A A$ degradation in pasteurized cupuaçu nectar $\left(18{ }^{\circ} \mathrm{Brix}, \mathrm{pH} 3.2\right)$

\begin{tabular}{ccccccc}
\hline Nectar & Fitted model & $\begin{array}{c}E_{a} \\
(\mathrm{~kJ} / \mathrm{mol})\end{array}$ & $\begin{array}{c}K_{25^{\circ} \mathrm{C}} \\
\left(\mathrm{days}^{-1}\right)\end{array}$ & $C_{0}$ & $C_{\infty}$ & $R^{2}$ Adj. \\
\hline $\mathrm{AA}_{R}$ & $\frac{C-C_{\infty}}{C_{0}-C_{\infty}}=e^{-k t}$ & $-34 \pm 6$ & $0.006 \pm 0.003$ & $0.92 \pm 0.01$ & $0.43 \pm 0.19$ & 0.997 \\
\hline $\mathrm{AA}_{F}$ & $\frac{C}{C_{0}}=e^{-k t}$ & $30 \pm 17$ & $0.0016 \pm 0.0004$ & $0.99 \pm 0.01$ & - & 0.994 \\
\hline $\mathrm{CO}_{2}$ & $\frac{C-C_{\infty}}{C_{0}-C_{\infty}}=e^{-k t}$ & $67 \pm 17$ & $1.94 \pm 0.94$ & $0.97 \pm 0.03$ & $0.55 \pm 0.01$ & 0.99 \\
\hline
\end{tabular}


168 | Vieira and Silva

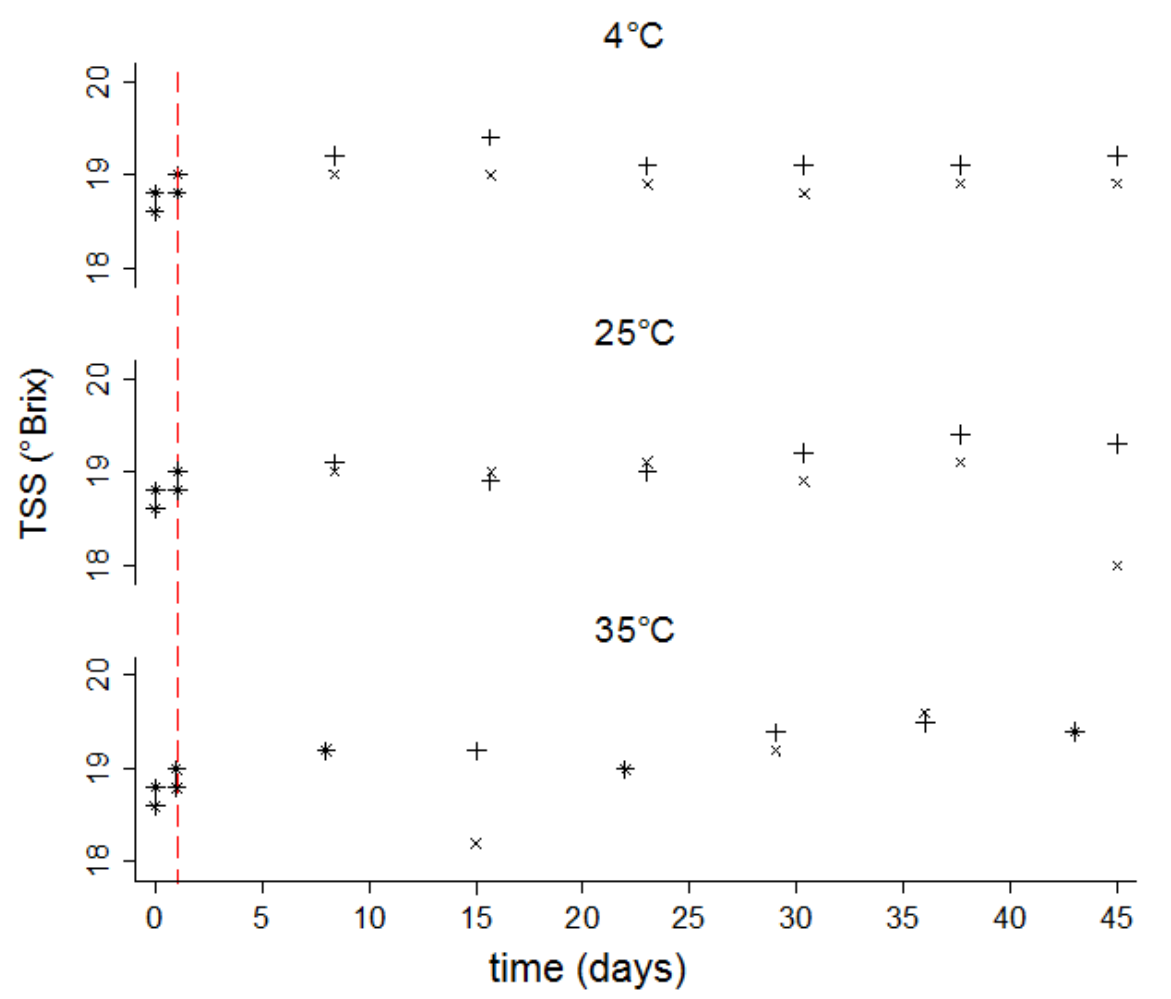

Figure 4: Evolution of TSS ( ${ }^{\circ}$ Brix) with storage time and at temperatures of 4, 25 and $35{ }^{\circ} \mathrm{C}$. Batch R $(+)$, batch $\mathrm{F}(\mathrm{x})$. Day 0 is before pasteurization and day 1 (marked with a vertical red dashed line) is the first day of storage.

$D O$, initially with a concentration of $10 \mathrm{ppm}$, decreased with the storage time to a residual value of $\cong 4 \mathrm{ppm}$. In fact, the decrease of dissolved oxygen is caused by two factors, where a part might have diffused from the nectar to the headspace and a part might have reacted with $A A$. This behavior was already verified by Singh, Heldman, and Kirk (1976), who reported a shelf life study on a liquid infant formula. They concluded that $A A$ degradation followed a first order reaction kinetics, when oxygen was present

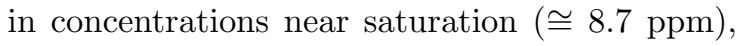
but in the presence of a residual concentration $(0.2 \mathrm{ppm})$ the reaction was considered of second order. Also, in a study on the kinetics of degradation of ascorbic acid in orange juice during storage at refrigeration temperatures, published by Polydera, Stoforos, and Taoukis (2003), a similar behavior was observed, but the change in the rate of degradation was modeled as zeroorder. In fact, the residual concentration of oxygen is reached much earlier for higher temperatures, which leads to the unexpected result that the higher the temperature the lower the degradation rate, giving rise to negative activation energies. Several studies have been reported on whether it is valid to accept a negative $E a$. Van der Plancken, Van Loey, and Hendrickx (2007) reported exactly this antagonistic effect, of temperature and reaction rate, on the application of high pressure combined with temperature, which was interpreted as revealing a reaction with two steps, where the second is irreversible. In another study, also on the application of high pressure and temperature (Verlinde, Oey, Deborggraeve, Hendrickx, \& Van Loey, 2009), it 
Cupuaçu nectar stable storage $\mid 169$
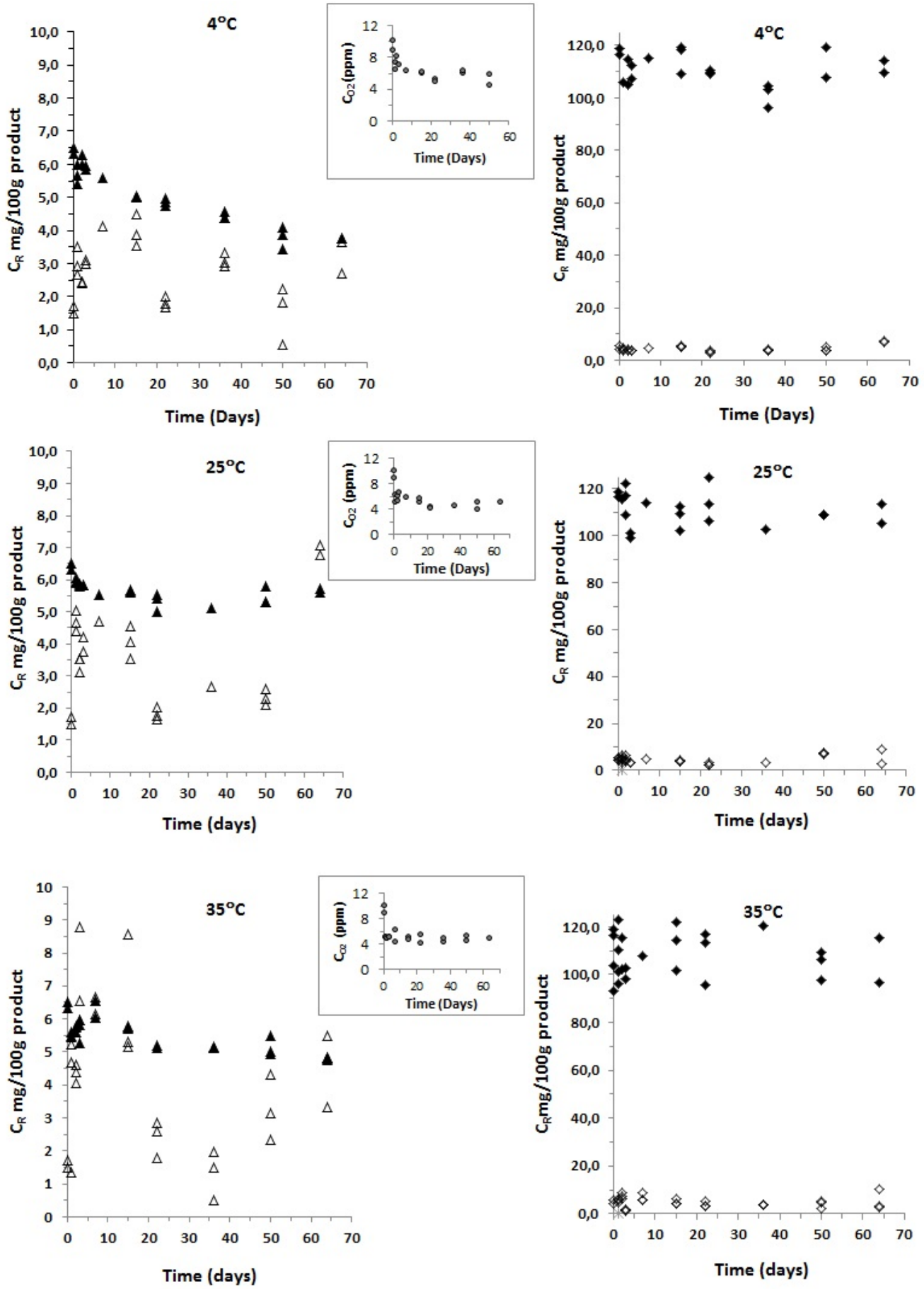

Figure 5: Experimental values of Vitamin $\mathrm{C}$ degradation as a function of storage temperature $(4,25$ and $35{ }^{\circ} \mathrm{C}$ ). Left hand graphs present the $\mathrm{R}$ nectar: $(\boldsymbol{\Delta}) A A,(\triangle) D H A A$. Right hand graphs present the $\mathrm{F}$ nectar: ( $) A A$ added and $(\diamond) D H A A$. Dissolved $\mathrm{O}_{2}, D O$, is represented by (o)(small graph). 

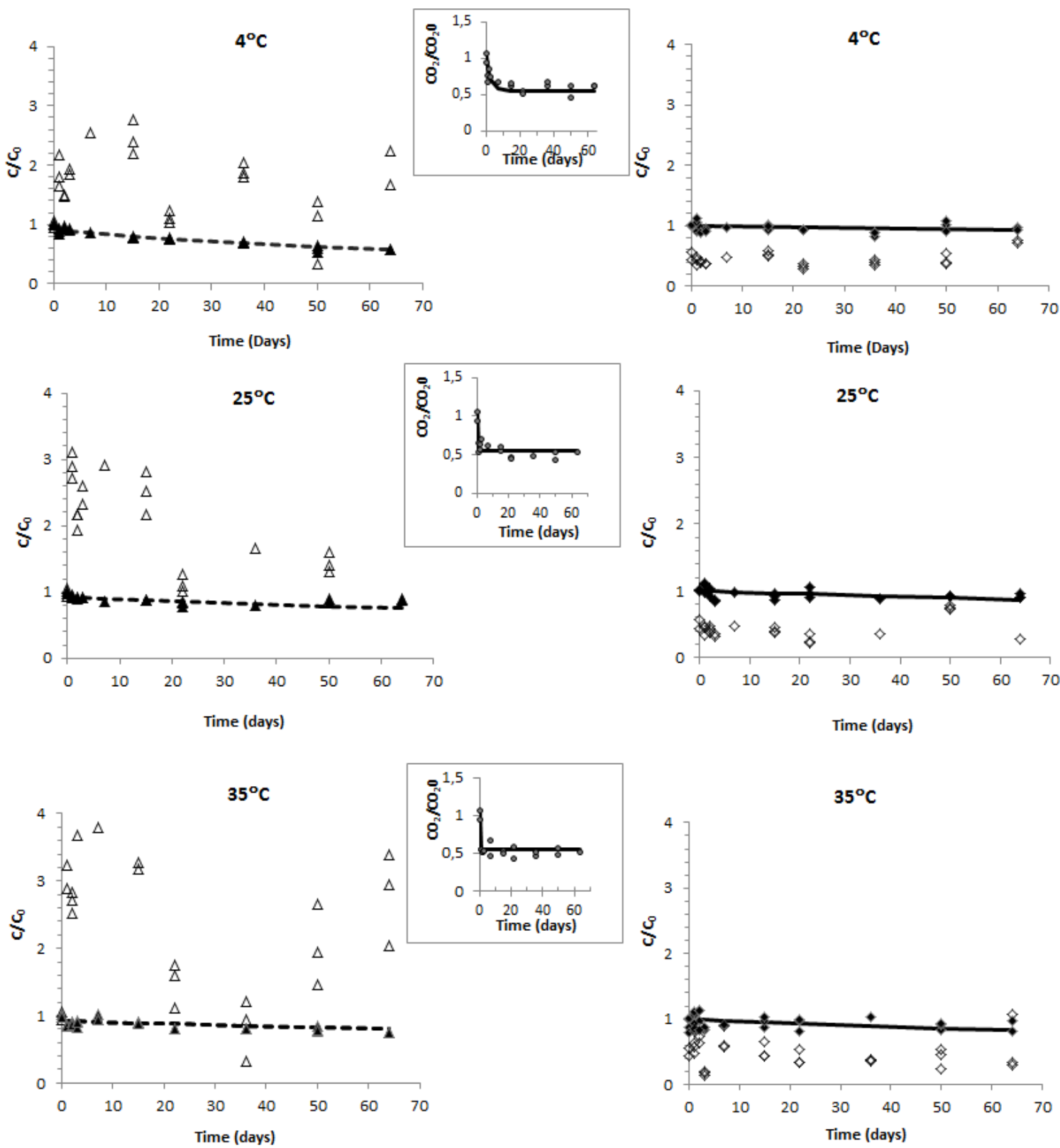

Figure 6: Behavior of $A A$ degradation in the regular cupuaçu nectar and when fortified with synthetic $A A$, as a function of dissolved oxygen and storage temperature $\left(4,25\right.$ and $\left.35^{\circ} \mathrm{C}\right)$. Left hand graphs present the $\mathrm{R}$ nectar: experimental values of $A A$ are represented by a $(\mathbf{\Delta})$, the model predicted values of $A A$ by a dashed line and experimental values of $D H A A$ by a $(\triangle)$. Right hand graphs present the $\mathrm{F}$ nectar: the experimental values when synthetic $A A$ was added represented by a $(\bullet)$, model predicted values of $A A$ by a full line, DHAA by $(\diamond)$. Dissolved $\mathrm{O}_{2}, D O$, for both batches, is represented by ( $($ ) (small graph). The model predicted values of DO are represented by a black continuous line. 
is implied that the observed inversion of the Arrhenius behaviour is due to the existence of a reverse reaction, which results in depletion of the activated complex formed, becoming so sensitive to temperature at high pressures, that its rate sharply rises with increasing temperature. In our case, it is well known that there is a reversible mechanism between ascorbic and dehydroascorbic acids, and it could be stated that in a long storage period the presence of a low concentration of oxygen also renders the reverse reaction very sensitive to temperature and increases the rate so much with temperature that less degradation of $A A$ results at increasing temperatures, as there is production of $A A$ at the same time from $D H A A$.

On the other hand, in an orange juice continuously aerated for 36 hours (Manso, Oliveira, Oliveira, \& Frias, 2001), the degradation kinetics followed a first order reaction model $\left(k_{32.5^{\circ} \mathrm{C}}=\right.$ $0.888 \pm 0.043$ days $^{-1}, \quad E a=71.0 \pm 3.8 \mathrm{~kJ} / \mathrm{mol}$ ) with more than $50 \%$ degradation obtained after less than 8 hours when stored at $45{ }^{\circ} \mathrm{C}$, indicating that the presence of oxygen promotes a much faster degradation reaction, where the rate has a positive Arrhenius dependence on temperature. In fact, the vitamin $\mathrm{C}$ mechanism of degradation is extremely complex, with over 50 low molecular weight products of vitamin $\mathrm{C}$ degradation having been found (Gregory, J. F. III, 1996). Depending on the environment, different pathways (aerobic or anaerobic) can be found, and depending on the packaging characteristics (especially if copper is present), the reaction can be catalyzed or not. Gregory, J. F. III (1996) stated that the anaerobic pathway is commonly found to happen in canned vegetables or fruit juices, precisely after the residual oxygen concentration has been reached.

The evolution of dissolved oxygen with time and storage temperature was modeled as a fractional conversion model and its kinetics determined $\left(E a=67 \pm 17 \mathrm{~kJ} / \mathrm{mol}, \mathrm{k} 25{ }^{\circ} \mathrm{C}=1.94 \pm 0.94\right.$ days $^{-1}$ ) (see Table 1 and Fig. 6). This model had already been used by Ahrne et al. (1997) in modeling dissolved oxygen in orange juice packed in cartons.

In both cases ( $\mathrm{R}$ and $\mathrm{F}$ nectars), DHAA was present from the beginning to the end of storage, meaning that the product is not in danger of browning, as already mentioned in the introduction.

\section{Conclusions}

From this study it was concluded that both the regular $(\mathrm{R})$ and fortified (F) cupuaçu pasteurized nectars were safe, since the TPC, yeasts and molds remained below the initial counts before pasteurization. Acidity and TSS also did not change during this period. HMF was not found in the nectars throughout the study, therefore it can be concluded that the pasteurization temperature was not high enough to produce this compound and browning did not occur.

In nectar $\mathrm{R}$ both the oxygen dissolved and existing in the headspace played a very important role in the behavior of vitamin $\mathrm{C}$ evolution. At lower temperatures the oxygen dissolved in the nectar diffuses much slower than at 25 and $35{ }^{\circ} \mathrm{C}$ to the headspace and is more available to react with ascorbic acid, contributing to its degradation at a higher rate. The evolution of dissolved oxygen with time and storage temperature was modeled as a fractional conversion model and its kinetics determined. A reversible first order model fitted very well the experimental data for $A A$ degradation. For the fortified nectar, hardly any $A A$ decrease was noticed at $4{ }^{\circ} \mathrm{C}$, but when stored at the higher temperatures a slight decrease was noticed. A first order model was used to model this behavior in the nectar $(E a=30 \pm 17 \mathrm{~kJ} / \mathrm{mol}$, $k_{25^{\circ} C}=0.0016 \pm 0.0004$ days $\left.^{-1}\right)$. In both cases, $D H A A$ was present from the beginning to the end of storage, meaning that the product is not in danger of browning.

If an extended shelf life period is required, it is recommended to use glass bottles to pack the nectar, and the hot fill procedure as the preservation method, as less oxygen is introduced in the nectar. Storage at 25 or $35{ }^{\circ} \mathrm{C}$ seems to present less problems than storage at $4{ }^{\circ} \mathrm{C}$ (with a decrease in retention of $50 \%$ ), since oxygen reaches its residual concentration faster at higher temperatures and $A A$ retention remains above 80 $\%$. Addition of synthetic $A A$ would bring nutritional benefits, which is also very important from a marketing stand point, and from this study it was concluded that its content will just slightly 
decrease during shelf life.

\section{References}

Ahrne, L., Oliveira, F., Manso, M., Drumond, M., Oste, R., \& Gekas, V. (1997). Modelling of dissolved oxygen concentration during storage of packaged liquid foods. Journal of Food Engineering, 34(2), 213224. doi:10.1016/S0260-8774(97)00082-4

Arabshahi, A. \& Lund, D. B. (1985). Considerations in calculating kinetic parameters from experimental data. Journal of Food Process Engineering, 7(4), 239-251. doi:10.1111/j. 1745-4530.1985.tb00308.x

Ayhan, Z., Yeom, H., Zhang, Q., \& Min, D. (2001). Flavor, color, and vitamin c retention of pulsed electric field processed orange juice in different packaging materials. Journal of Agricultural and Food Chemistry, 49(2), 669-674. doi:10.1021/ jf000984b

Barbosa, W., Hunn, A., Nazare, R., \& Nagata, I. (1979). Estudos fisicos e quimicos dos frutos: bacuri (platonia insignis), cupuacu (theobroma grandiflorum) e muruci (byrsonima crassifolia). Anais Congresso Brasileiro Fruticola, 5, 797-808.

Bissett, O. W. \& Berry, R. E. (1975). Ascorbic acid retention in orange juice as related to container type. Journal of Food Science, 40(1), 178-180. doi:10.1111/j.1365-2621. 1975.tb03765.x

Damasceno, L. F., Fernandes, F. A. N., Magalhaes, M. M. A., \& Brito, E. S. (2008). Evaluation and optimization of non enzymatic browning of cajuina during thermal treatment. Brazilian Journal of Chemical Engineering, 25(2), 313-320.

Eison-Perchonok, M. H. \& Downes, T. W. (1982). Kinetics of ascorbic-acid autoxidation as a function of dissolved-oxygen concentration and temperature. Journal of Food Science, 47(3), 765-\&. doi:10.1111/j. 1365-2621.1982.tb12710.x

FDA. (1998). Hazard analysis critical control point (HACCP): procedures for the safe and sanitary processing and importing of juice. Department of Health and Human Services. 63 FR 20450.

Gregory, J. F. III. (1996). Vitamins Chapter 8. In Fennema, O.(Eds). Food Chemistry. 3rd edition, Marcel Dekker: New York, 538610.

Hsieh, Y. H. P. \& Harris, N. D. (1993). Effect of sucrose on oxygen-uptake of ascorbicacid in a closed aqueous system. Journal of Agricultural and Food Chemistry, 41(2), 259-262. doi:10.1021/jf00026a023

Hsieh, Y. P. \& Harris, N. D. (1987). Oxidation of ascorbic-acid in copper-catalyzed sucrose solutions. Journal of Food Science, 52(5), 1384-1386. doi:10.1111/j.1365-2621.1987. tb14088.x

IPQ. (1987). Microbiologia Alimentar. Contagem de bolores e leveduras. Parte 1: Incubação a $25{ }^{\circ} \mathrm{C}$. NP $3277-1$.

ISO 2173. (1978). International organization of standardization - ISO. Fruit and vegetable products: Determination of soluble solids content - Refractometric method. ISO, 1978. $2173 \mathrm{p}$.

ISO 4833. (2003). Microbiology of food and animal feeding stuffs-horizontal method for the enumeration of microorganisms-colonycount technique at $30{ }^{\circ} \mathrm{C}$. International Organisation for Standardisation. Geneva, Switzerland.

ISO 750. (1998). International organization of standardization - ISO. Fruit and vegetable products: Determination of Titrable Acidity. 2. ed. ISO, 1998. 750 p.

Jung, M. Y., Kim, S. K., \& Kim, S. Y. (1995). Riboflavin-sensitized photooxidation of ascorbic-acid - kinetics and aminoacid effects. Food Chemistry, 53(4), 397403. doi:10.1016/0308-8146(95)99834-M

Manso, M., Oliveira, F., Oliveira, J., \& Frias, J. (2001). Modelling ascorbic acid thermal degradation and browning in orange juice under aerobic conditions. International Journal of Food Science and Technology, 36(3), 303-312. doi:10.1046/j.13652621.2001.t01-1-00460.x

Marshall, M., Nagy, S., \& Rouseff, B. (1986). Factors impacting on the quality of stored citrus fruit beverages. Developments in Food Science, 2(12), 237-254. 
Mcintyre, S., Ikawa, J. Y., Parkinson, N., Haglund, J., \& Lee, J. (1995). Characteristics of an acidophilic bacillus strain isolated from shelf-stable juices. Journal of Food Protection, 58(3), 319-321.

Oliveira, M. L. S. (1981). Contribuição ao aproveitamento industrial do cupuaçu (Theobroma grandiflorum Schum.) (Doctoral dissertation, M. Sc. thesis, Univ. Federal Ceará, Fortaleza, Brasil).

Pedro, A. M. K. \& Ferreira, M. M. C. (2006). Multivariate accelerated shelf-life testing: a novel approach for determining the shelflife of foods. Journal of Chemometrics, 20(1-2), 76-83. doi:10.1002/cem.995

Polydera, A., Stoforos, N., \& Taoukis, P. (2003). Comparative shelf life study and vitamin c loss kinetics in pasteurised and high pressure processed reconstituted orange juice. Journal of Food Engineering, 60(1), 21-29. doi:10.1016/S0260-8774(03)00006-2

Sahbaz, F. \& Somer, G. (1993). The effect of citrate anions on the kinetics of cupric ion catalyzed oxidation of ascorbic-acid. Food Chemistry, 47(4), 345-349. doi:10.1016/ 0308-8146(93)90175-F

Sampedro, F., Geveke, D. J., Fan, X., Rodrigo, D., \& Zhang, Q. H. (2009). Shelf-life study of an orange juice-milk based beverage after pef and thermal processing. Journal of Food Science, 74(2), S107-S112. doi:10 . 1111/j.1750-3841.2009.01068.x

Sawamura, M., Takemoto, K., Matsuzaki, Y., Ukeda, H., \& Kusunose, H. (1994). Identification of two degradation products from aqueous dehydroascorbic acid. Journal of Agricultural and Food Chemistry, 42(5), 1200-1203.

Silva, C. L. M. (1998). Étude pluridisciplinaire de transformations de fruits amazoniens en vue de leur valeur par les organizations paysannes existantes. EU-STD3-ERB-TS3-CT94-0300. Cupuaçu (Theobroma grandiflorum). Final Report. Escola Superior de Biotecnologia. Universidade Católica Portuguesa.

Silva, F. \& Silva, C. (1997). Quality optimization of hot filled pasteurized fruit purees: container characteristics and filling temperatures. Journal of Food Engineering, 32(4),
351-364. doi:10 . 1016 / S0260 - 8774(97 ) 00031-9

Singh, R. P., Heldman, D. R., \& Kirk, J. R. (1976). Kinetics of quality degradation ascorbic-acid oxidation in infant formula during storage. Journal of Food Science, 41(2), 304-308. doi:10.1111/j.1365-2621. 1976.tb00606.x

Solberg, P., Castberg, H., \& Osmunsen, J. (1990). Packaging systems for fruit juices and non-carbonated beverages. Chapter 12. In Hicks, D. (Eds.) Production and Packaging of Non-Carbonated Fruit Juices and Fruit Beverages, First ed.; (pp 330-351). United Kingdom: Blackie and Son, Ltd.

Stata Corporation. (1995). Stata Statistical Software: Release 4.0 college station.

Tannenbaum, S. (1976). Ascorbic acid. Chapter 7. In Fennema, O. (Eds.) Principles of Food Science. Part I. Food Chemistry, 2nd ed.;(pp 477-544). New York: Marcel Dekker.

Tchango, J., Tailliez, R., Eb, P., Njine, T., \& Hornez, J. (1997). Heat resistance of the spoilage yeasts candida pelliculosa and kloeckera apis and pasteurization values for some tropical fruit juices and nectars. Food Microbiology, 14(1), 93-99. doi:10.1006/ fmic.1996.0065

Van der Plancken, I., Van Loey, A., \& Hendrickx, M. E. (2007). Kinetic study on the combined effect of high pressure and temperature on the physico-chemical properties of egg white proteins. Journal of Food Engineering, 78(1), 206-216. doi:10.1016/j. jfoodeng.2005.09.018

Verlinde, P. H. C. J., Oey, I., Deborggraeve, W. M., Hendrickx, M. E., \& Van Loey, A. M. (2009). Mechanism and related kinetics of 5-methyltetrahydrofolic acid degradation during combined high hydrostatic pressure-thermal treatments. Journal of Agricultural and Food Chemistry, 57(15), 6803-6814. doi:10.1021/jf900832g

Vieira, M., Teixeira, A., \& Silva, C. (2000). Mathematical modeling of the thermal degradation kinetics of vitamin $\mathrm{c}$ in cupuacu (theobroma grandiflorum) nectar. Journal of Food Engineering, 43(1), 1-7. doi:10.1016/S0260-8774(99)00121-1 
Wang, X. Y., Seib, P. A., \& Ra, K. S. (1995). L-ascorbic acid and its 2-phosphorylated derivatives in selected foods: vitamin c fortification and antioxidant properties. Journal of Food Science, 60(6), 1295-1300. doi:10.1111/j.1365-2621.1995.tb04578.x

Zapata, S. \& Dufour, J. P. (1992). Ascorbic, dehydroascorbic and isoascorbic acid simultaneous determinations by reverse phase ion interaction HPLC. Journal of Food Science, 57(2), 506-511. doi:10.1111/j.13652621.1992.tb05527.x 